\section{Nusinersen in spinal muscular atrophy type 1 from neonates to young adult: 1-year data from three Asia-Pacific regions}

\section{INTRODUCTION}

Spinal muscular atrophy type I (SMA1) is the most common and severest form of SMA. According to natural history studies, affected babies never achieve independent sitting, and the combined median age of death or permanent ventilation is 13.5 months. ${ }^{1}$ Nusinersen, an antisense oligonucleotide that modifies survival motor neuron (SMN2) splicing to enhance fulllength SMN protein expression, is the first of many promising approved SMA treatments. The ENDEAR nusinersen clinical trial on SMA1 in patients aged $<7$ months showed promising motor milestone achievements and improved survival. ${ }^{2}$ Through this multinational study, we provide the first Asian real-world data on patients with SMA1 after 1 year of nusinersen treatment.

\section{METHODS}

This retrospective observational cohort study, involving eight institutes in three Asian regions (Hong Kong SAR, Taiwan and South Korea) evaluated the baseline clinical characteristics, motor outcomes and changes in ventilation needs of participating patients with SMA1, from pre-treatment (M0) to 6 months (M6) and 10 months (M10) post-treatment. All participants started nusinersen under the Expanded Access Programme (EAP) between 2017 and 2019. Baseline information-newborn screening where applicable, SMN1 mutation, SMN2 copies, gestational age at birth, sex, age of symptom onset, body weight, respiratory support, feeding status, musculoskeletal status and age of first nusinersen-was collected. The motor outcomes before and after nusinersen initiation, measured by Hammersmith InfantNeurologic Examination Part 2 motor milestones score (HINE-2), CHOP INTEND and motor milestone achievements, were recorded. We used CHOP INTEND increased $\geq 4$ points and HINE- 2 gained $\geq 5$ points as clinical meaningful improvement. ${ }^{2}$ The study was approved by the ethics committees of individual regions.

\section{Statistical analysis}

Baseline demographics and clinical characteristics were presented using descriptive statistics. Changes in the median scores of HINE-2 and CHOP INTEND were calculated using one-way repeated measures ANOVA and paired t-test for quantitative and qualitative variables, respectively. Missing data were excluded. A p value of $<0.05$ was regarded as statistically significant. A multiple regression model was performed to find the predictor variables of motor outcomes. We used IBM SPSS Statistics V.25 for analyses.

\section{RESULTS}

Online supplemental table 1 presents the demographic data and clinical characteristics of the 40 patients with SMA1. Twothirds of patients had two SMN2 copies. Over half of the cohort (57\%) began nusinersen $\leq 2$ years old. For the nine patients $(22.5 \%)$ identified by newborn screening, eight started nusinersen $<7$ months. All patients started nusinersen at the symptomatic stage. The median nusinersen initiation age was 20 months (range 0.35-294 months).

\section{Survival and motor outcome}

1. $95 \%$ of patients continued the EAP programme

One patient died before M6 due to respiratory failure. Another patient dropped out before M10 due to lack of improvement. Both had two SMN2 copies (online supplemental table 2).

2. Patients who started nusinersen at aged $\leq 2$ years had better motor milestone gains

Of the patients who started nusinersen at $\leq 2$ years old, $36.4 \%$ (8/22 patients) achieved unassisted sitting; three (13.6\%) also attained assisted standing. At M10, $61.1 \%$ (11/18 patients) gained $\geq 5$ points in HINE-2, with the median gain of 7.5. In contrast, for those who started nusinersen $>2$ years old, only $6.7 \%$ (1/15 patients) achieved unassisted sitting. At M10, only $7.1 \%$ ( $1 / 14$ patients) gained $\geq 5$ points in HINE-2 with the median gain of 0.5 only (table 1) (online supplemental figure 1). Despite having one SMN2 copy, the patient who started nusinersen aged 2 months gained 5 HINE-2 points at M10.

3. Patients with three copies of SMN2 had better motor responses than those with two copies.

In table 1, patient with three SMN2 copies had greater increases in median HINE-2 scores from baseline at M6 and M10 compared with those with two copies $(p=0.003)$. A more significant difference was observed in CHOP INTEND $(p<0.001)$ (online supplemental table 3, figure 2). At M10, more patients $(87.5 \%$; $7 / 8$ ) with three SMN2 copies had CHOP INTEND gained $\geq 4$ points, compared with only $54.5 \%$ (6/11 patients) in those with two SMN2 copies. The only patient with nusinersen started $>2$ years of age and achieved independent sitting was an adult patient with spinal fusion, with three SMN2 copies who first received nusinersen at $241 / 2$ years old.

2. Newborn screening, disease duration and HINE-2 baseline scores predict milestone gains.

We used Pearson correlation to check the correlation of each risk factor with delta HINE-2 (M10-M0) and delta CHOP INTEND (M10-M0) scores. A multiple linear regression model was used to understand whether disease duration (period between symptom onset and treatment initiation), SMN2 copies, baseline scores and newborn screening if present, accounted for the variability in Delta HINE-2 and Delta CHOP INTEND scores. The univariate analysis showed that Delta HINE-2 scores were negatively correlated with disease duration $(\mathrm{r}=-0.391, \mathrm{p}=0.027, \mathrm{n}=32)$ and positively correlated with baseline HINE-2 scores $(\mathrm{r}=0.377, \mathrm{p}=0.033, \mathrm{n}=32)$ and newborn screening $(\mathrm{r}=0.557, \mathrm{p}=0.001, \mathrm{n}=32)$. The multiple linear regression showed that only newborn screening was independently associated with delta HINE-2 scores $\left(r^{2}: 0.479\right.$, adjusted beta: $\left.0.424, p=0.009\right)$. We could not find any predictor variable for the Delta CHOP INTEND (M10-M0) (online supplemental table 4).

5. Different needs of respiratory support post-treatment (online supplemental table $5)$.

\section{DISCUSSION}

We found patients with SMA1 from the neonatal to adult age benefit from nusinersen treatment. Newborn screening, shorter disease duration and higher baseline HINE-2 score may predict better milestone gains. In the ENDEAR study, ${ }^{2}$ $28 \%$ of patients gained $\geq 5$ HINE- 2 points (M10) and a mean nusinersen starting age of 5.4 months. For our eight patients who started nusinersen at $<7$ months old and with two SMN2 copies, they had an earlier mean nusinersen starting age at 2.7 months, and a higher percentage (61.1\%; 5/8 patients) gained $\geq 5$ HINE-2 points (M10). While newborn screenings enable the identification of affected presymptomatic babies, ${ }^{3}$ our patients began treatment only after symptom onset. As illustrated by the NURTURE study ${ }^{4}$ and the AVXS-101 phase 1/2A clinical trials, ${ }^{5}$ 
Table 1 HINE-2 evolution of the patients according to SMN2 copy number and age of nusinersen initiation

\begin{tabular}{|c|c|c|c|c|}
\hline Characteristics & $\begin{array}{l}\text { Total } \\
(n=40)\end{array}$ & $\begin{array}{l}\text { One copy of SMN2 } \\
(n=1)\end{array}$ & $\begin{array}{l}\text { Two copies of SMN2 } \\
(\mathrm{n}=25)\end{array}$ & $\begin{array}{l}\text { Three copies of SMN2 } \\
(n=14)\end{array}$ \\
\hline Sex, M:F, n & $18: 22$ & $1: 0$ & $10: 15$ & $7: 7$ \\
\hline Age at symptom onset & $3.0(0.0-6.0)$ & 0.0 & $2.0(0.0-6.0)$ & $4.5(1.0-6.0)$ \\
\hline Age at nusinersen initiation & $20.0(0.35-294.0)$ & 2.0 & $19.0(0.35-140.0)$ & $25.3(4.0-294.0)$ \\
\hline Disease duration before nusinersen & $17.5(0.0-291.5)$ & 2.0 & $16.0(0.35-140.0)$ & $17.5(0.0-291.5)$ \\
\hline \multicolumn{5}{|l|}{ HINE-2 score } \\
\hline M0 & $0.0(0.0-4.0), n=37$ & $0.0, n=1$ & $0.0(0.0-2.0), n=24$ & $2.0(0.0-4.0), n=12$ \\
\hline M6 & $2.5(0.0-17.0), n=34$ & $4.0, n=1$ & $1.0(0.0-11.0), n=22$ & $4.0(1.0-17.0), n=11$ \\
\hline M10 & $4.0(0.0-24.0), n=32$ & $5.0, n=1$ & $2.5(0.0-20.0), n=20$ & $4.0(1.0-24.0), n=11$ \\
\hline Time effect $p$ value & $<0.001$ & 1 & $<0.001$ & 0.002 \\
\hline Delta M6-M0 & $2.0(0.0-16.0), p<0.001$ & 4.0 & $1.0(0.0-11.0), p=0.002$ & $2.0(1.0-16.0), p=0.019$ \\
\hline Delta M10-M0 & $3.0(0.0-20.0), p<0.001$ & 5.0 & $2.5(0.0-20.0), p=0.003$ & $3.0(1.0-20.0), p=0.010$ \\
\hline
\end{tabular}

HINE-2 score (age $\leq 7$ months old at onset of treatment)

\begin{tabular}{|c|c|}
\hline M0 & $0.0(0.0-4.0), n=13$ \\
\hline M6 & $6.0(2.0-16.0), n=11$ \\
\hline M10 & $11.0(3.0-24.0), n=11$ \\
\hline Time effect $p$ value & $<0.001$ \\
\hline Delta M6-M0 & $6.0(2.0-12.0), p<0.001$ \\
\hline Delta M10-M0 & $9.0(3.0-20.0), p<0.001$ \\
\hline HINE-2 score (age $\leq$ & tment) \\
\hline M0 & $0.0(0.0-4.0), n=22$ \\
\hline M6 & $5.0(0.0-17.0), n=19$ \\
\hline M10 & $9.0(0.0-24.0), n=18$ \\
\hline Time effect $p$ value & $<0.001$ \\
\hline Delta M6-M0 & $4.0(0.0-16.0), p<0.001$ \\
\hline Delta M10-M0 & $7.5(0.0-20.0), p<0.001$ \\
\hline HINE-2 score (age > & atment) \\
\hline M0 & $0.0(0.0-2.0), n=15$ \\
\hline M6 & $1.0(0.0-4.0), n=15$ \\
\hline M10 & $0.5(0.0-7.0), n=14$ \\
\hline Time effect $p$ value & 0.002 \\
\hline Delta M6-M0 & $1.0(0.0-2.0), p=0.003$ \\
\hline Delta M10-M0 & $0.5(0.0-5.0), p=0.013$ \\
\hline
\end{tabular}

* Data are listed as median (range) in months.

$\ddagger$ One-way repeated measures ANOVA.

$\S$ Paired t-test.

I Multiple regression demonstrated that there was significant difference in the changes of the HINE-2 scores, delta M6-M0 and delta M10-M0, between the two groups with two and three SMN2 copies with the standard coefficients $\beta$ of 0.263 ( $p=0.003$ ).

† Three patients were not included in the HINE-2 MO analysis, due to the following reasons: one patient did not have baseline HINE-2 performed; two patients did not have HINE-2 performed.

HINE-2, Hammersmith Infant Neurologic Examination Part 2 motor milestones score; M0, before treatment; M6, 6 months of treatment; M10, 10 months of treatment; SMN, survival motor neuron.

the best motor outcomes for SMA1 treatment are to asymptomatic affected babies and those with earlier dosing aged $<3$ months. Support for earliest treatment is therefore necessary.

\section{CONCLUSION}

This multinational collaborative retrospective observational cohort study in Asia provides real-world data on firstyear treatment that nusinersen is safe and beneficial to patients with SMA1 from the neonatal to adult age. Newborn screening that promotes early treatment initiation can maximise treatment efficacy.

Sophelia Hoi-Shan Chan $\odot^{1},{ }^{1}$ Jong-Hee Chae, ${ }^{2,3}$ Yin-Hsiu Chien, ${ }^{4}$ Tae-Sung Ko, ${ }^{5}$ Jee Hun Lee, ${ }^{6}$ Yun Jeong Lee, ${ }^{7}$ Sang Ook Nam, Yuh-Jyh Jong 9,10,11
'Department of Paediatrics and Adolescent Medicine, Queen Mary Hospital, The University of Hong Kong, Hong Kong SAR, China

${ }^{2}$ Department of Pediatrics, Seoul National University Children's Hospital, Seoul National University College of Medicine, Seoul, The Republic of Korea

${ }^{3}$ Rare Disease Center, Seoul National University Hospital, Seoul, The Republic of Korea

${ }^{4}$ Department of Medical Genetics and Pediatrics, National Taiwan University Hospital, Taipei, Taiwan ${ }^{5}$ Department of Pediatrics, Asan Medical Center Children's Hospital, University of Ulsan College of Medicine, Seoul, The Republic of Korea

${ }^{6}$ Department of Pediatrics, Samsung Medical Center, Sungkyunkwan University School of Medicine, Seoul, The Republic of Korea

${ }^{7}$ Department of Pediatrics, Kyungpook National University Hospital, Kyungpook National University College of Medicine, Daegu, The Republic of Korea ${ }^{8}$ Department of Pediatrics, Pusan National University Children's Hospital, Pusan National University College of Medicine, Yangsan, The Republic of Korea

${ }^{9}$ Departments of Pediatrics and Laboratory Medicine, and Translational Research Center of Neuromuscular
Diseases, Kaohsiung University Medicine Hospital, Kaohsiung Medical University, Kaohsiung, Taiwan ${ }^{10}$ Graduate Institute of Clinical Medicine, College of Medicine, Kaohsiung Medical University, Kaohsiung, Taiwan

${ }^{11}$ Department of Biological Science and Technology, National Chiao Tung University, Hsinchu, Taiwan

Correspondence to Dr Sophelia Hoi-Shan Chan, Department of Paediatrics and Adolescent Medicine, Queen Mary Hospital, The University of Hong Kong, Hong Kong SAR, China; sophehs@hku.hk and Professor Yuh-Jyh Jong, Departments of Pediatrics and Laboratory Medicine, and Translational Research Center of Neuromuscular Diseases, Kaohsiung University Medicine Hospital, Kaohsiung Medical University, Kaohsiung, Taiwan; yjjong@gap.kmu.edu.tw

Acknowledgements The authors would like to thank all the SMA patients and their families for their participation in this SMA EAP study; Mr Wilfred Wong for his advice on the data analysis; Ms Rachel BY Lee for her professional English editing support.

Collaborators Queen Mary Hospital, LKS Faculty of Medicine, The University of Hong Kong, HKSAR: 
Department of Paediatrics and Adolescent Medicine - Godfrey Chi-Fung CHAN, So-Lun LEE, Yiu-Ki NG, Christy CHAU, Ka Ka SIU, Wilfred WONG, Ronnie CHENG, Yuk-Shuen CHAU, Chun-Wai LO. Department of Orthopaedics and Traumatology - Everlyn KUONG, Kenny KWAN. Physiotherapy Department - Pricillia LAM, Pearl CHENG, Maggie NG, Yvonne YUE, Nathan KWONG. Seoul National University Children's Hospital, Seoul National University College of Medicine, Seoul, South Korea: Department of Pediatrics -Young kyu SHIM, Soo Yeon KIM, Huung Ik SHIN, Jee Hun LEE, Anna CHO. National Taiwan University Hospital, National Taiwan University, Taipei, Taiwan: Department of Medical Genetics and Pediatrics -Wen-Chin WENG, Wuh-Liang HWU, Jeng-Yi SHIEH, Hsi-Wen HUANG. Kaohsiung University Medicine Hospital, Kaohsiung Medicine University, Kaohsiung, Taiwan: Departments of Pediatrics and Laboratory Medicine, and Translational Research Center of Neuromuscular Diseases - WenChen LIANG, Hao-Wei CHUNG, Jong-Hau HSU, Wan-Yi HSU, Wan-Yi HSU, Chen-Hua WANG, Hsiang-Hung SHIH, Yun-Hui CHOU, Yun-Hui CHOU, Tzu-Hsiu HUANG, Su LEE, Yi-Ching WU.

Contributors SH-SC, J-HC, Y-HC, JHL, T-SK, YJL, SON, Y-JJ are the principal investigators of the SMA EAP study in their medical centres. SH-SC designed the study, undertook data collection, analysis and evaluation, initial drafting, revision and finalisation of the manuscript. J-HC collected and evaluated data and assisted data collection from the other five centres in the South Korea, assisted the analysis of data interpretation and revised the manuscript. Y-HC collected the data and assisted the analysis of the data interpretation and revised the manuscript. T-SK, SON, JHL, YJL collected and evaluated data. Y-JJ designed the study, collected the data and assisted the analysis of data interpretation and the revision of the manuscript.

Funding This study is supported by a donation funding on 'Diagnosis and therapy development of rare neurological diseases and neuromuscular diseases' (20009121) received by SHS Chan.

Competing interests $\mathrm{SH}-\mathrm{SC}$ received honorarium for serving on scientific advisory board of Biogen and Norvartis; for presentations at academic meetings. J-HC received honorarium for serving on scientific advisory board from Biogen and Norvartis; and research grant from Biogen. Y-HC received research funding and honorarium for presentations and consultancy from Biogen. Y-JJ received honorarium for consulting, serving on a scientific advisory board, speaking, or other activities for Biogen and Novartis; research grants for SMA natural history in Taiwan, and clinical trial funding from Biogen. He is also the president of non-profit organisation Taiwan SMA Families.

Patient consent for publication Not required.

Provenance and peer review Not commissioned; externally peer reviewed.

Supplemental material This content has been supplied by the author(s). It has not been vetted by BMJ Publishing Group Limited (BMJ) and may not have been peer-reviewed. Any opinions or recommendations discussed are solely those of the author(s) and are not endorsed by BMJ. BMJ disclaims all liability and responsibility arising from any reliance placed on the content. Where the content includes any translated material, BMJ does not warrant the accuracy and reliability of the translations (including but not limited to local regulations, clinical guidelines, terminology, drug names and drug dosages), and is not responsible for any error and/or omissions arising from translation and adaptation or otherwise.

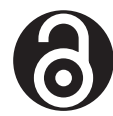

\section{OPEN ACCESS}

Open access This is an open access article distributed in accordance with the Creative Commons Attribution Non Commercial (CC BY-NC 4.0) license, which permits others to distribute, remix, adapt, build upon this work non-commercially, and license their derivative works on different terms, provided the original work is properly cited, appropriate credit is given, any changes made indicated, and the use is non-commercial. See: http:// creativecommons.org/licenses/by-nc/4.0/.

(C) Author(s) (or their employer(s)) 2021. Re-use permitted under CC BY-NC. No commercial re-use. See rights and permissions. Published by BMJ.
- Additional material is published online only. To view, please visit the journal online (http://dx.doi.org/ 10.1136/jnnp-2020-324532).

Check for updates

To cite Chan SH-S, Chae J-H, Chien Y-H, et al. J Neurol Neurosurg Psychiatry Epub ahead of print: [please include Day Month Year]. doi:10.1136/jnnp-2020324532

Received 9 July 2020

Revised 4 January 2021

Accepted 18 January 2021

J Neurol Neurosurg Psychiatry 2021;0:1-3. doi:10.1136/jnnp-2020-324532

ORCID iD

Sophelia Hoi-Shan Chan http://orcid.org/0000-00022990-0163

\section{REFERENCES}

1 Kolb SJ, Coffey CS, Yankey JW, et al. Natural history of infantile-onset spinal muscular atrophy. Ann Neurol 2017;82:883-91.

2 Finkel RS, Mercuri E, Darras BT, et al. Nusinersen versus sham control in infantile-onset spinal muscular atrophy. N Engl J Med 2017;377:1723-32.

3 Chien Y-H, Chiang S-C, Weng W-C, et al. Presymptomatic diagnosis of spinal muscular atrophy through newborn screening. J Pediatr 2017;190:124-9.

4 De Vivo DC, Bertini E, Swoboda KJ, et al. Nusinersen initiated in infants during the presymptomatic stage of spinal muscular atrophy: interim efficacy and safety results from the phase 2 nurture study. Neuromuscul Disord 2019:29:842-56.

5 Lowes LP, Alfano LN, Arnold WD, et al. Impact of age and motor function in a phase $1 / 2 \mathrm{~A}$ study of infants with SMA type 1 receiving single-dose gene replacement therapy. Pediatr Neurol 2019;98:39-45. 